\title{
RISCO INVISÍVEL: TRABALHO E SUBJETIVIDADE NO SETOR
} ELÉTRICO

\author{
RIESGO INVISIBLE: TRABAJO Y SUBJETIVIDAD EN EL SECTOR \\ ELECTRICO \\ INVISIBLE RISK: WORK AND SUBJECTIVITY IN THE ELECTRICITY \\ SECTOR
}

http://dx.doi.org/10.1590/1807-0310/2017v29131134

Julice Salvagni

Universidade Federal do Rio Grande do Sul, Porto Alegre/RS, Brasil

Marília Veríssimo Veronese

Universidade do Vale do Rio dos Sinos, São Leopoldo/RS, Brasil

\begin{abstract}
RESUMO
Este estudo se origina de uma pesquisa que abordou a noção de risco no trabalho no setor elétrico. O termo "risco invisível" surgiu do discurso dos trabalhadores do setor, referindo-se à eletricidade que não pode ser vista, mas oferece riscos específicos. Dá-se ênfase a uma análise da noção de risco, enquanto fenômeno da modernidade, mas passando também pela discussão da confiança básica e da segurança ontológica. Ao relacionar esse marco teórico com a realidade do trabalho no setor elétrico, entra em cena o articulador teórico dos mecanismos de defesa, através da psicodinâmica do trabalho. Do ponto de vista político, é importante refletir sobre a realidade da segurança no âmbito das relações de trabalho, já que os trabalhadores são expostos a riscos específicos em cada atividade. A reflexão teórica e observação empírica constante são um caminho para pensar intervenções no âmbito da dimensão sociopsicológica do risco no trabalho.
\end{abstract}

Palavras-chave: risco invisível; trabalho; subjetividade; mecanismos de defesa; setor elétrico.

\section{RESUMEN}

Este estudio se deriva de la investigación que se dirigió a la noción de riesgo en el trabajo en el sector eléctrico. El término "riesgo invisible" surgió de la voz de los trabajadores del sector, haciendo referencia a la electricidad, que no puede ser vista, pero, plantea riesgos específicos. Se hace necesario el análisis del concepto de riesgo como un fenómeno de la modernidad, pero también a través de la discusión de la confianza básica y la seguridad ontológica. Para relacionar este marco teórico con la realidad del trabajo en el sector eléctrico, entra en escena la articulación teórica de los mecanismos de defensa a través de la psicodinámica del trabajo. Desde el punto de vista político, es importante reflexionar a respecto de la realidad de la seguridad en el contexto de las relaciones laborales, ya que los trabajadores están expuestos a riesgos específicos de cada actividad. La reflexión teórica y la observación empírica consistente es una manera de pensar acerca de las intervenciones para la dimensión socio - psicológico de riesgo en el trabajo.

Palabras clave: riesgo invisible; trabajo; subjetividad; Los mecanismos de defensa; sector eléctrico.

\begin{abstract}
This study is part of a research work that approach aspects related to the work risk in the electricity sector. The term "invisible risk" came from the speech of the workers, referring to electricity, which can not be seen, but offers specific risks. We emphasize an analysis of the concept of risk as a phenomenon of modernity, but also through the discussion of basic trust and ontological security. By relating this theoretical framework with the reality of working in the electricity sector, enters the scene the theoretical articulation of defense mechanisms, through psychodynamics of work. From a political standpoint, it is important to reflect on the reality of security in the context of labor relations, as workers are exposed to specific risks in each activity. The theoretical reflection and empirical constant observation are one way to think about interventions within the socio-psychological dimension of risk at work.
\end{abstract}

Keywords: Invisible risk; work; subjectivity; defense mechanisms; electricity sector. 


\section{Introdução}

Este trabalho tem origem em uma dissertação de mestrado defendida no Programa de Pós-Graduação em Ciências Sociais da UNISINOS-RS, intitulada "Risco Invisível: um estudo sobre a subjetividade dos trabalhadores do setor elétrico". A relação a ser apresentada neste estudo, acerca do entendimento do risco invisível enquanto temática constituinte das relações de trabalho, diz respeito a uma categoria que surgiu a partir da pesquisa e propõe a ampliação do entendimento do risco no trabalho no que tange à produção subjetiva dos trabalhadores. Neste aspecto, enfatizamos a produção de sentido sobre o risco baseados na fala dos trabalhadores.

"Risco invisível" foi um termo que surgiu nas conversas com trabalhadores do setor elétrico. Referiam-se à eletricidade, que, por não poder ser vista, segundo eles, deve ser respeitada. Aos poucos fomos percebendo que o invisível, tanto quanto o risco, referia-se a uma conjuntura de fatores aos quais esses trabalhadores estavam expostos, o que tornava o campo do risco invisível bem mais amplo do que simplesmente as questões sobre a própria eletricidade em si.

$\mathrm{Na}$ pesquisa, buscamos conhecer como é trabalhar sob o risco constante, e invisível, de acidentes de trabalho e em que medida isso é transformado em sofrimento psíquico pelo trabalhador. Mesmo porque, ao passar do tempo e ao avançar da tecnologia, os processos de trabalho foram se aperfeiçoando, mas o risco de adoecimento ou acidente não deixou de estar presente nas organizações de variados segmentos e portes (Possamai \& Guareschi, 2007).

Além do risco de acidentes que mutilam o corpo do trabalhador, compreendemos que os riscos seguem na esfera do "invisível" - totalmente relacionados com os fatores sócio-psicológicos. Por tal motivo, ao mesmo tempo que o risco é um elemento constitutivo da subjetividade dos trabalhadores do setor, as experiências pessoais do sujeito vão compor sua representação do risco no trabalho, e é o que se produz nessa relação que nos propomos a analisar aqui. $\mathrm{O}$ contato com o risco é produtor de muita ansiedade, angústia e sofrimento, dado que este é invisível, pode não ser reconhecido e, por conseguinte, não passível de ser controlado pelo trabalhador.

O setor de serviços elétricos no Brasil passou por grandes mudanças nos últimos anos, as quais são subjetivadas especialmente pelos que trabalham nestas instituições. Os processos de privatização e as mudanças que eles implicaram aumentaram o nível de cobrança e exigência com a realização do trabalho, provocando alterações drásticas nas empresas e, consequentemente, na vida dos trabalhadores. Eles estão agora submetidos a uma cobrança por tempo de conclusão de trabalho bem maior do que quando eram ligados à estatal. Isso acontece porque a geradora de energia (neste caso uma empresa gaúcha que assumiu a região) pressiona as montadoras por preços menores e prazos mais estreitos de entrega dos serviços. A coerção da maior para a menor acaba se efetivando pela concorrência estabelecida entre as instaladoras, que precisam se manter obtendo lucros.

Num estudo do setor elétrico sobre a CERJ Companhia Elétrica do Rio de Janeiro -, Nogueira (1999) afirma que, com a privatização, o Estado "parou de investir na manutenção e expansão do sistema, acarretando numa degradação progressiva das instalações e dos equipamentos e uma precarização das condições de trabalho" (p. 52).

Quando a privatização estava formalizada, Nogueira destaca que houve mudanças nas condições de vida e de trabalho dos referidos trabalhadores e também de seus dependentes. No caso dos que se realocaram em empresas terceirizadas, houve uma redução do salário e dos adicionais, tendo perdido muitas conquistas e mesmo alguns direitos trabalhistas que eram considerados até como privilégios por essa categoria profissional. (Nogueira, 1999, p. 54)

A pesquisa compreendeu um estudo de caso no qual se utilizaram técnicas como entrevistas individuais, grupos focais, filmagens do trabalho para discutir nos grupos, análise de documentos e preenchimento de diários de campo. Como referencial analítico e organizativo dos dados, valemo-nos da análise de conteúdo temático proposta por Laurence Bardin (1995), que é uma das ferramentas em meio à análise de conteúdo que nos permitiu uma compreensão de cunho semântico - ou relativa ao sentido - do que foi obtido junto aos informantes. Estes trabalham em uma empresa privada, localizada na serra gaúcha, uma empresa de montagem de redes elétricas, cujo trabalho tem uma característica importante: os homens eventualmente trabalham com redes vivas, energizadas, ou seja, sem cortar a energia ao mexer em postes e outros pontos de energia elétrica. $\mathrm{O}$ risco que se configura, portanto, é bastante claro e está "a espreita", mesmo não podendo ser visto.

A fala do técnico de segurança no trabalho enfatiza o seguinte:

Nessa área, tem que ter todos os cuidados mínimos e exagerados às vezes pra evitar um acidente. Então é uma coisa que tu não enxerga, uma coisa que tu não tem noção do que é, só vai ver quando tu sofrer um acidente. (Teodoro) 
Participaram dezessete homens, com idades entre 22 e 52 anos, alguns poucos com mais de 10 anos de trabalho na empresa, mas a maioria com pouco tempo, mostrando a rotatividade existente no setor. Apenas um deles é natural de Garibaldi-RS. A maioria veio de outras cidades em busca de trabalho e passa a semana no alojamento nas dependências da empresa, indo para casa aos finais de semana. Em torno de 60\% deles não terminaram o ensino fundamental, e alguns têm inclusive um processo de alfabetização precário, $o$ que dificulta muito sua carreira no setor. As exigências do trabalho com equipes reduzidas fazem com que haja muita rotatividade de funcionários. $\mathrm{O}$ espectro do risco invisível ronda a todos eles de forma individual e coletiva. Diz Teodoro:

Eu acho que o maior risco nosso é quando a gente não vê o risco. O problema é quando essa rotina se transforma tanta que tu não consegue mais ver o que é arriscado e o que não é, que tu acha que tudo é fácil, tudo é normal, ai é o preocupante. (Teodoro)

Quanto ao aprofundamento teórico em torno do risco invisível, que foi uma das categorias de análise e que será detalhado no texto, optamos pela abordagem teórica de Anthony Giddens (1989; 2002). O autor trata o risco a partir de uma concepção ampla o suficiente que nos permite abarcar nossas inferências aos apontamentos específicos dos trabalhadores, discutindo-os concomitantemente com a teoria.

Utilizamos as teorizações sociológicas acerca do trabalho com base psicanalítica - como a psicopatologia do trabalho de Christophe Dejours (1988; 1994; 1999; 2003) - que traz um aspecto mais subjetivo da vida psíquica do trabalhador e que também dialoga com a teoria social crítica, através da ação comunicativa de Habermas e com a filosofia crítica, utilizando o conceito de banalização do mal de Hannah Arendt. Sobretudo, descortinamos aspectos da eufemização do risco em relação com o acionamento dos mecanismos de defesa.

$\mathrm{O}$ risco visto por esta perspectiva toma proporções que vão muito além do que é pensado em nome da segurança do trabalho na atualidade e nos mostra que há muitas mudanças a serem feitas antes de afirmar que a prevenção acontece.

\section{Compreensão teórico-analítica do risco}

O que é visivel, plenamente inteligível, é o caráter firme, audacioso, mesmo em sua tranquilidade, de todos esses rostos crestados pelo sol, pela chuva e pelo vento.

Charles Baudelaire (Sobre a modernidade)
Os riscos, de várias ordens, representam boa parte dos males que cercam a sociedade contemporânea. O risco é trabalhado em sentido amplo na sociologia que tomaremos como base para o entendimento nas rotinas laborais dele produtoras.

Para Ulrich Beck (2002, p. 5), que constrói o entendimento do risco como algo mais ligado à transformação dos fatores ambientais, "es el enfoque moderno de la previsión y control de consecuencias futuras de la acción humana, con diversas consecuencias no deseadas de la modernalizaciín radicalizada". Tal concepção, embora mais ampla e que se refere ao risco da sociedade global, indica a noção de controle das consequências futuras. Ou seja, trata o risco como algo que anuncia uma situação de perigo e, portanto, deve ter a atenção a fim de ser evitado.

De acordo com o autor, entre os aspectos que estão ligados à sociedade do risco global, poderíamos salientar a extensão do setor informal, a flexibilização do trabalho, a desregulamentação de setores da economia e relações de trabalho, a perda da legitimidade do Estado, o crescimento do desemprego e do subemprego, as intervenções das multinacionais e o em parte consequente aumento da criminalidade e dos elevados índices de violência.

Beck trata da questão do trabalho não como central no entendimento do risco, mas o considera como fator de mudanças sociais que merecem destaque enquanto produtoras de novas subjetividades. Da mesma forma, o que entendemos por risco, para muito além da situação de perigo em que os trabalhadores do setor elétrico estão expostos, diz respeito a esta gama de fatores mais diversos que vão compor o contexto no qual é experimentado o sofrimento do trabalhador, por sujeitos concretos.

No intuito de propor a diferenciação da unidade de risco e perigo, trazemos o conceito proposto por Serrano (2009), autor que o discute numa perspectiva sociológica. Para ele,

ao utilizar a diferença risco/perigo, partimos do pressuposto de que todo observador precisa de uma diferença ou distinção, porque de outra forma não poderia caracterizar o que pretende observar. Entretanto, um observador não pode observar o outro lado da diferença quando está usando a diferença, porque a transição de um lado para outro necessita de tempo. É por isso que quem observa com o olhar do risco não pode - ao mesmo tempo - observar com o olhar do perigo. (Serrano, 2009, p. 234)

De tal modo,

a diferença risco/perigo indica que, para ser definido o conceito de risco, precisamos do conceito de perigo 
e o oposto. Por exemplo, uma inundação é um perigo, porém, aquele que constrói sua casa no leito de um rio expõe-se a um risco. Um furacão é um perigo, mas quem provoca o aquecimento global se (e nos) expõe a um risco. A inundação, o terremoto e o furacão são um mesmo fenômeno, mas podem ser contemplados a partir de dois pontos de vista. (Serrano, 2009, pp. 233-234)

Apenas por volta do século XV se introduz o conceito de risco para caracterizar situações que, se supõe, não estavam bem caracterizadas por termos como sorte, perigo, acaso ou medo. Ou seja, o risco é um complexo cultural, conceito próprio da modernidade (Serrano, 2009). Pensando no nosso objeto de estudo central, o risco dos trabalhadores do setor elétrico, poderíamos definir, conforme a proposta do autor, que a eletricidade é perigosa, mas o fato de trabalhar com a eletricidade - assim como a todos os demais fatores aqui implícitos - expõe os funcionários a uma situação de risco.

O autor ainda considera outros aspectos do risco, como a sua dimensão econômica, ecológica e etc, descrição que não faremos neste texto. Contudo, é importante ressaltar o conceito de risco, para o nosso entendimento, é amplo, situacional e que implica numa vasta cadeia de relações. Isso faz com que as situações de risco sejam tão difíceis de serem descritas e, principalmente, de serem controladas.

Anthony Giddens (2002) empreende uma reflexão a respeito da segurança ontológica, percorrendo a noção de risco no sentido amplo, podendo ser aplicado a diversas situações. Para ele, "a manutenção da vida, nos sentidos corporal e de saúde psicológica, está inerentemente sujeita ao risco" (Giddens, 2002, p. 43). E a confiança básica "é um dispositivo de triagem em relação a riscos e perigos que cercam a ação e a interação. É o principal suporte emocional de uma carapaça defensiva ou casulo protetor que todos os indivíduos normais carregam como meio de prosseguir com os assuntos cotidianos" (Giddens, 2002, p. 43).

$\mathrm{O}$ entendimento da confiança básica pode ser transposto, mantendo-se as devidas proporções de cada contexto, para diversas formas sociais, como é o caso do trabalho. Se os trabalhadores puderem estabelecer um vínculo de confiança com a empresa, que se mostra preocupada com o bem-estar do funcionário, por exemplo, cedendo equipamentos de proteção individual e estimulando o seu uso e a sua importância, já estaria sendo proporcionada, seguindo a lógica de Giddens, alguma noção de segurança ontológica.

Usando esta lógica como representação em nosso estudo junto ao trabalho do eletricitário, as empresas também teriam a função de criar situações que permitam aos trabalhadores desenvolverem uma segurança do trabalho. Para tanto, o risco deve ser reconhecido, nomeado e tratado às claras com os funcionários, o que nem sempre sucede. A passagem discursiva do risco - invisível para visível - é essencial na produção da segurança ontológica e na consequente diminuição da ansiedade dos funcionários. Ora, se diminui a ansiedade, também se reduz o sofrimento psíquico e, desta forma, alguns riscos.

Anthony Giddens (2002) entende como invisível "o que não pode ser posto em palavras" - sendo os intercâmbios com pessoas e objetos ao nível da prática diária - o que vai constituir a condição necessária do que pode ser dito, dos significados envolvidos na consciência prática (p. 45). Assim, o trabalho de tornar o invisível algo visível se dá na prática discursiva, o que vai possibilitar a tomada de sentido e a produção de significados.

Podemos entender este trabalho, de tornar o risco invisível em algo visível, ou dizível, como a condição para a necessária elaboração do sofrimento psíquico. Algo que fica na ordem do invisível - e, portanto, indizível - vai ser o grande produtor da ansiedade e da falta de segurança ontológica. De qualquer maneira, "todos os indivíduos desenvolvem um referencial de segurança ontológica de alguma espécie, baseado em vários tipos de rotinas. As pessoas lidam com perigos, e os medos associados a eles, em termos das "fórmulas" emocionais e comportamentais" (Giddens, 2002, p. 47). Isto é, ainda segundo o autor, a sensação de segurança "é muito mais importante no ser humano do que os impulsos resultantes das sensações de fome ou de sede" (2002, p. 47). Isso se justifica porque a segurança ontológica, aqui compreendida em sentido muito amplo, é a condição necessária para que o indivíduo possa viver com um sentimento de proteção, que é fundamental para que ele possa desfrutar de certa tranquilidade.

Naturalmente, tal sensação de segurança não vai ser constante e os momentos de sofrimento e angústia vão existir, não só no ambiente de trabalho, como em todos os aspectos da vida em geral, dos quais são categorias constitutivas. Assim, "como base de um sistema de administração de tensão, a polaridade confiança/desconfiança é organizada em torno de relações entre projeção e introjeção como mecanismos da personalidade" (Giddens, 1989, pp. 33-34).

Uma relativa sensação de segurança é criada pela rotina do contato com a eletricidade. Todavia, não é preciso um grande evento para que esta suposta sensação de segurança dê espaço à insegurança (ou 
desconfiança) frente à relação com o trabalho ali colocada, fazendo com que o trabalhador utilize-se de mecanismos de defesa. Um exemplo de situação provocadora desta instabilidade é quando acontece um "quase acidente", um evento sem gravidade, mas que poderia ter sido um acidente grave. Isso já é suficiente para trazer à tona uma mudança nos mecanismos de apreensão da realidade do trabalho.

\section{Os mecanismos de defesa na sua relação com o risco}

As estratégias coletivas de defesa analisadas por Christophe Dejours (1999) incluem o mecanismo na sua operação individual, numa perspectiva psicanalítica. Diz o autor:

As estratégias individuais de defesa, como a repressão pulsional entre os trabalhadores submetidos a um trabalho repetitivo com imposição de prazos ... sempre apresentam um risco potencial para a autonomia subjetiva e moral. Assim, o trabalho se revela essencialmente ambivalente. Pode causar infelicidade, alienação ou doença mental, mas pode também ser mediador da auto-realização, de sublimação e de saúde. (Dejours, 1999, p. 98)

\section{Porém, as estratégias individuais de defesa}

têm importante papel na adaptação ao sofrimento, mas pouca influência na violência social, visto que são de natureza individual. A psicodinâmica do trabalho descobriu também a existência de estratégias coletivas de defesa, que são estratégias construídas coletivamente. Se, mesmo nesse caso, a vivência do sofrimento permanece fundamentalmente singular, as defesas podem ser objeto de cooperação. As estratégias coletivas de defesa contribuem de maneira decisiva para a coerção do coletivo de trabalho, pois trabalhar é não apenas ter uma atividade, mas também viver: viver a experiência da pressão, viver em comum, enfrentar a resistência do real, construir o sentido do trabalho, da situação e do sofrimento. (Dejours, 1999, p. 103)

Por esta razão, partimos da premissa de que a negação do risco por parte dos trabalhadores do setor elétrico se deriva, em grande parte, da ativação inconsciente dos mecanismos de defesa, essenciais para que o trabalhador consiga manter-se trabalhando em contato com o risco. Um bom exemplo que podemos trazer deriva de um dos momentos do grupo focal com uma das equipes, enquanto discutíamos os vídeos trazidos por eles.

A certa altura da pesquisa, surgiu a ideia de gravar em vídeo situações de trabalho para assistir e discutir durante os grupos focais. Os trabalhadores levavam as câmeras e filmavam o que lhes parecia relevante.
Visualizando os vídeos na execução do próprio trabalho, estava registrada uma brincadeira flagrando motorista da equipe que dormia na calçada durante o intervalo do almoço. Na situação, os demais componentes do grupo o cercaram com as fitas usadas para marcar a área de trabalho (fitas plásticas de cores preta e amarela) e as colocaram próximo a ele um cartaz escrito "local proibido". Quando ríamos da brincadeira feita pela equipe, um deles menciona: "Só assim para conseguir trabalhar" (Cláudio).

A afirmativa ressalta a importância dos mecanismos de defesa para a saúde desses trabalhadores. Através das brincadeiras que podem parecer tolas e ingênuas, o fato de trabalhar em local perigoso produz a percepção de nunca saber como se retornará de uma atividade. Outros exemplos, como sobre o relacionamento de grupos, trataremos em profundidade na categoria que discute cooperação. Ali, vemos que há a criação de conflito também como uma maneira de desviar o foco colocado no risco da atividade. Evitar o contato direto com o conteúdo do risco surge como condição de poder realizar o trabalho.

Tal mecanismo põe o funcionário em risco na medida em que pode lhe conferir uma "segurança" que ele não tem e, assim, deixá-lo à vontade para arriscarse nos momentos em que deveriam ter maior controle de segurança. Muitos dos funcionários, referindose ao momento do acidente, tratam o episódio como um "descuido", ou um "esquecimento". Entretanto, podemos tratar esses aspectos como um momento no qual o funcionário estava operando sob o "comando" dos seus próprios mecanismos de defesa; seja individual ou coletivo, pode produzir a eufemização do risco e a aproximação de situações perigosas.

Notamos que a reclamação é constante entre os trabalhadores do setor elétrico, que se descrevem na maior parte do tempo, conforme observado nos grupos focais, como descontentes ou desgostosos com o seu trabalho. Entendemos que isso tem relação direta com o fato de trabalharem com o risco e precisarem, de alguma maneira, se defender desse "peso" que é estar em constante tensão.

Sendo o trabalho um componente - dentre muitos outros - na constituição da subjetividade, poderá ser um espaço onde a produção da sensação de segurança (ou sua falta) vai abarcar diretamente a constituição de uma subjetividade de mesma espécie. Aqui mora a relevância de se estudar a dimensão dos riscos invisíveis enquanto produtores diretos de sofrimento psíquico no trabalho.

Christophe Dejours, quando trata do "fator humano", afirma a dificuldade dos profissionais 
psicólogos ou sociólogos na inserção da temática da segurança do trabalho. "Engajar-se nesse campo é marchar a descoberto, sem a proteção do conhecimento" (Dejours, 2003, p. 20). Aqui, ele discute sobre a dificuldade de se manter um trabalho na área da segurança, que demanda um amplo conhecimento do homem, ou das ciências humanas, e do processo de trabalho que vem da ergonomia, ou das ciências da natureza.

Esta problemática epistemológica, dado que ainda não compreende uma área de estudo que dê conta da demanda posta, faz com que lancemos a questão: quais as dimensões da conduta humana elucidadas pelas ciências do homem no trabalho, que deveriam ser reconduzidas em toda teoria do fator humano, independente de sua orientação e de sua metodologia? (Dejours, 2003, p. 20).

Até então, os acidentes de trabalho costumam ser tratados ou como um erro por parte do trabalhador que não cumpriu o procedimento, ou como uma insuficiência no próprio procedimento, razão do aumento das exigências de uso de equipamentos por parte dos trabalhadores. Na nova proposta do trabalho, sobretudo se tratando do risco, deve-se admitir que "o trabalho não decorre jamais da "execução", mas que todo trabalho implica uma parte de gestão da distância entre a organização do trabalho prescrito e a organização do trabalho real, isto é, que ele decorre ainda, por um lado, de uma dimensão estritamente humana, e mesmo inter-humana, resultante da ação" (Dejours, 2003, p. 25).

É possível admitir a subjetividade do trabalhador como parte integrante do risco invisível. Sendo assim, esta dimensão da subjetividade, quando incluída na elaboração de propostas de intervenção nas empresas, contribui para amenizar as formas de sofrimento psíquico que também colocam em risco a saúde (e a vida) do sujeito no ambiente de trabalho. "Trata-se, pois, de direcionar desta vez a investigação científica para os processos intrassubjetivos e intersubjetivos e para as relações entre os indivíduos e a organização" (Dejours, 2003, p. 26).

Portanto, entendemos que todo ou qualquer fator psicossocial que possa vir a abalar o sujeito deve fazer parte deste entendimento de risco. Tomando como exemplo, o histórico dos acidentes fatais na empresa pesquisada nos mostra que num dos acidentes, por exemplo, o funcionário, ao sair de casa para ir trabalhar, teve uma briga séria com a filha. Além de todos os fatores técnicos, as variações psicossociológicas devem ser observadas, principalmente por se tratar de um trabalho tão perigoso.

\section{Modernidade e eletricidade: a fala dos trabalhadores}

\author{
A disposição de arriscar, porém, não mais deve \\ ser domínio apenas de capitalistas de risco ou \\ individuos extremamente aventureiros. O risco vai se \\ tornando uma necessidade diária enfrentada pelas \\ massas. \\ Richard Sennett
}

Anthony Giddens (2002), refletindo acerca das questões do risco na modernidade, menciona a importância do homem enquanto produtor da própria (in)segurança no mundo. Nessa perspectiva, podemos pensar na eletricidade como um ganho da modernidade - no sentido da sua vasta ampliação e aplicação mas, por outro lado, também enquanto fonte de risco, especialmente para quem trabalha para que tenhamos acesso à luz elétrica. Todos estão imersos nos riscos que tais oportunidades que criamos nos oferecem; cada coisa que é criada agride o meio ambiente ou o próprio ser humano, de alguma forma, ao mesmo tempo que pode beneficiá-lo. $\mathrm{O}$ entendimento do risco, então, comporta essa ambiguidade, e mesmo contradição. Assim, "a noção de risco se torna central numa sociedade que está deixando o passado, o modo tradicional de fazer as coisas, e que se abre para o futuro problemático. Essa afirmação se aplica tanto em ambientes de risco institucionalizado quanto a outras áreas" (Giddens, 2002, p. 104).

Há uma transformação da modernidade no sentido da criação de outras preocupações sociais, o aumento do foco no elemento "risco" é uma delas. Anthony Giddens (2002) cita, por exemplo, a criação de seguros, que fazem parte de um fenômeno mais geral relacionado ao controle do tempo. Desse modo, o futuro se torna cada vez mais imprevisível e, por que não dizer, temeroso. Isso ganha aplicabilidade também na análise do nosso objeto. Por isso,

pensar em termos de risco é vital para aferir até que ponto os resultados reais poderão vir a divergir das previsões e projetos. A aferição do risco requer precisão e mesmo quantificação, mas por sua própria natureza é imperfeita. Dado o caráter móvel das instituições modernas, associado à natureza mutável e muitas vezes controversa dos sistemas abstratos, a maioria das formas de aferição dos ricos, em verdade, contém muitos imponderáveis. (Giddens, 2002, p. 11)

Buscamos contornar o risco com a maior quantidade de variáveis possível, justamente cientes da dificuldade de se fazer aferições, de lá ou de cá. Os riscos são sempre constituídos por um conjunto de variáveis (e fatores) muito extenso. 
Como o risco e tentativas de estimativas de risco são tão fundamentais para a colonização do futuro, o seu estudo pode nos dizer muito sobre estudos centrais da modernidade. Diversos fatores fazem parte disso: a redução dos riscos que ameaçam a vida dos indivíduos, como consequência da expansão da segurança na atividade de risco institucionalmente confinado; o monitoramento do risco como aspecto-chave da refletividade da modernidade; a criação de riscos de alta consequência resultantes da globalização; e a operação de tudo isso contra um pano de fundo de um "clima de risco" inerentemente instável. (Giddens, 2002, p. 109)

Os trabalhadores do setor elétrico normalmente reproduzem o discurso de que "antigamente não precisava de nada disso, cada um fazia o trabalho como queria e subíamos no poste até de bermuda e chinelo". Hoje, só é possível entrar em contato com a rede elétrica fazendo o uso de uma roupa completa elaborada com um material anti-chamas, além das botinas, capacete, óculos, luvas especializadas (às vezes é preciso usar mais de uma, ou luvas diferentes para cada situação), protetor solar, etc. Sem falar da lista de equipamentos necessários para isolar a área (para que ninguém de fora se machuque). Isso faz com que eles afirmem: "Esse trabalho é mesmo muito perigoso... Nem tanto hoje, hoje que dá pra evitar os riscos assim..." (Valdir) e "é bastante risco, né, veio... (Alencar).

Somente no decorrer do século XX que estatísticas suficientes ficam disponíveis para mapear com alguma precisão aspectos que passam a ser considerados ameaçadores (Giddens, 2002). Ou seja, inventou-se uma nova concepção de risco no que ele chama de modernidade "alta" ou "tardia". Entre os aspectos que passaram a ganhar destaque nos registros de avanços na redução de riscos, se encontra, segundo o autor, "a ampla aceitação da segurança do trabalho". Mas na sequência do texto ele pondera que, como para os demais indicadores, isso não significou o cuidado exímio com a segurança do trabalho a ponto de evitar acidentes. No caso dos acidentes de trânsito, por exemplo, os últimos anos mostram o aumento do número de acidentes.

Assim,

a modernidade reduz o risco geral de certas áreas e modos de vida, mas ao mesmo tempo introduz novos parâmetros de risco, pouco conhecidos ou inteiramente desconhecidos em épocas anteriores. Esses parâmetros incluem riscos de alta consequência, derivados do caráter globalizado dos sistemas sociais da modernidade. O mundo moderno tardio - o mundo do que chamo de alta modernidade - é apocalíptico não porque se dirija inevitavelmente à calamidade, mas porque introduz riscos que as gerações anteriores não tiveram que enfrentar. (Giddens, 2002, pp. 11-12)

Nesta concepção, muito mais importante que destacar a "produção de riscos da modernidade" é fundamental descrever a produção subjetiva dos referidos riscos, incorporados constantemente pelos sujeitos. Aqui, não só aos sujeitos trabalhadores, já que, como vimos, a sociedade de modo geral está convivendo com o risco de maneira crescentemente intensa. Mas isso não elimina o fato de que algumas profissões envolvam um risco maior do que outras e, em se tratando do trabalho, os sujeitos ficam condicionados a lidar com o enfrentamento deste risco para manter-se empregados.

$\mathrm{O}$ autor ainda destaca os sistemas institucionais de risco que

afetam praticamente qualquer um, faça ele ou não parte desse sistema como "jogador" - mercados competitivos de produtos, de força de trabalho, de investimentos ou de capitais são os sistemas mais significativos. A diferença entre esses sistemas institucionalizados e outros parâmetros de risco é que eles são construídos pelo risco, não se tratando de uma situação em que ele é acidental. Ambientes institucionalizados de risco ligam riscos individuais e coletivos de muitas maneiras - as oportunidades individuais de vida, por exemplo, então agora diretamente amarradas à economia capital global. Mas em relação à presente discussão, esses ambientes são mais importantes sobre o que revelam sobre a forma de colonização do futuro. (Giddens, 2002, pp. 111-112)

Tais sistemas instrucionais de risco podem ser interpretados num aspecto mais global, como propõe o autor, mas também nos permitiremos extrapolar algumas inferências ao que se relaciona mais diretamente com a realidade dos trabalhadores do setor elétrico.

O mercado competitivo de produtos é um risco que afeta a sociedade de maneira integral, embora cada um vá estabelecer uma relação diferente com as pressões e demandas por ele postas. No caso do mundo do trabalho, a nova morfologia do trabalho possibilita que a precarização das relações laborais se estabeleça sem que isso gere grandes manifestações de conflito. Aliás, este pode ser considerado um dos riscos aceitos pela população, que não vê alternativa senão fazer parte do mercado de trabalho, mesmo que com todas as suas falhas, faltas e precariedades estabelecidas.

As relações de mercado estão ligadas aos mais variados campos da sociedade, de tal forma a se perder o controle, inevitavelmente, a cada "falha" 
recorrente. Um bom exemplo disso é a crise mundial que se estabeleceu em 2008/2009 e que ainda está provocando dificuldades pelo mundo afora. Quando essa crise se estabelece, em nível global, não só se percebe a fragilidade do atual sistema capitalista, como também a falta de controle social de qualquer nação, que pouco consegue fazer diante de situações nas quais a população se vê desprovida de condições mínimas de saúde, educação, alimentação etc. Pela fala dos trabalhadores, é possível notar a preocupação frente a momentos de abalo econômico e o consequente medo do futuro.

Outros riscos globais também podem ser ressaltados, como é o caso de doenças e epidemias, visto que fazem parte da vida de todos os seres humanos e, arriscamos dizer, são sentidos com mais preocupação por aqueles que carecem de segurança financeira, que não só lhes garantiria um melhor tratamento, como lhes deixaria, talvez, fora da área de risco.

Um bom exemplo disso é o advento de um surto de febre amarela em 2009. Nesta empresa que estudamos, os funcionários foram obrigados a vacinarem-se com preferência às demais pessoas da cidade. Isso porque estão normalmente trabalhando em lugares mais afastados e, portanto, são mais propensos ao contágio da doença por via do mosquito. $\mathrm{O}$ fato de tomar a vacina foi uma precaução tomada pela empresa, mas, em outras organizações de trabalho, a realidade foi diferente. De qualquer forma, isso chamou a atenção dos trabalhadores por dois motivos.

Primeiro, por eles saberem que não teriam acesso aos cuidados de saúde como outras pessoas, que podem pagar, o teriam apenas caso fossem acometidos por alguma doença. Em segundo lugar, eles se deram conta de que estavam mais próximos e vulneráveis ao contágio em função do seu trabalho. Isso causa, mais uma vez, um sentimento de maior fragilidade e exposição, se comparado com as pessoas que trabalham em escritórios com ambiente climatizado exemplo dado por eles mesmos.

A questão não é que a vida cotidiana seja hoje inerentemente mais arriscada que em épocas anteriores. É que, nas condições da modernidade, tanto para os leigos quanto para os peritos em campos específicos, pensar em termos de risco e estimativas de risco é um exercício quase permanente, e seu caráter é em parte imponderável. Vale lembrar que somos leigos em relação à vasta maioria dos sistemas especializados que interferem em nossa atividade diária. A proliferação de especializações anda junto com o avanço permanente das instituições modernas, e o crescente estreitamento das áreas de especialização parece um resultado inevitável do desenvolvimento técnico. Quanto mais se concentram especializações, tanto menor em termos relativos o campo em que qualquer indivíduo pode reivindicar competências; em outras áreas da vida ele estará na mesma situação que os demais. Mesmo no caso em que os peritos entram em consenso, por causa da natureza cambiante do saber moderno, os efeitos de "retorno" sobre o pensamento e prática leigos serão ambíguos e complicados. O clima de risco da modernidade é inquietante para todos; ninguém escapa. (Giddens, 2002, p. 117)

Outro exemplo, esse da área da saúde, trata do avanço das especialidades médicas, que, embora nos garanta alguma segurança no conhecimento mais específico dos atendimentos de saúde, nos obrigam (ou ao sistema público) a pagar por um número maior de consultas. Hoje é preciso ir a diversos médicos específicos para tratar de um único problema. Claro, tudo isso tem um preço e os valores acumulados desses serviços tornam o mundo mais arriscado no sentido de ser preciso cada vez mais ter condições financeiras para garantir que se tenha acesso aos serviços de demanda.

Uma dificuldade derivada dessa ampla área de especializações profissionais é a dependência do parecer, cada vez mais, de um maior número de profissionais, muitas vezes de áreas diferentes. Isso, seguramente, há de criar um dissenso. Os saberes mudam de acordo com novas descobertas, o que faz com que cada conhecimento tenha um prazo de validade possivelmente mais estreito.

Sobre os meus erros, as pessoas enxergam que eu tô
fazendo errado e me dizem que é pra fazer assim e
assim. E eu digo, será? E a pessoa diz sim, dá uma
olhada ali no manual que mudou, agora é assim.
Opa, mudou, resolvi fazer daquela forma e aí, vê se
ligaram. Ligaram? Sim, opa, então funciona! Quando
alguém via o meu erro, as pessoas me apontavam e eu
não ficava brabo com isso, queria aprender. (Bastião)

O trabalhador, nesta fala, aborda dois aspectos que são constantes para o trabalho: a negação de muitos deles quando apontados seus esquecimentos ou erros no cuidado com a segurança (o que entendemos à luz da compreensão sobre os mecanismos de defesa, em que cada vez que o risco é visualizado pode gerar no trabalhador uma atitude contrária à aceitação do mesmo) e as frequentes mudanças nos procedimentos, não só de segurança, bem como de construção da rede elétrica. Eles precisam estar em alerta permanente sob os padrões que vão sendo modificados. Uma tarefa um pouco complexa para quem já tem tantos detalhes para observar no seu dia de trabalho.

A questão central, neste aspecto, além de ser cobrado do trabalhador um grau de conhecimento que 
ele não tem, é que deve estar sempre muito atento e plenamente conectado com o seu trabalho. Ora, isso torna a função ainda mais próxima da ordem do impossível, psicologicamente.

Os responsáveis pela empresa sabem que os trabalhadores vão viver dias nos quais os problemas, sejam pessoais ou não, impedirão de ter essa atenção redobrada. A equipe está comunicada de que, nesta ocasião, deverá poupar o trabalhador de ações que envolvam maior risco. Porém, além de que isso, na prática, não acontece (a não ser em situações extremas), o trabalhador que se julgar despreparado para o serviço será taxado de preguiçoso ou vagabundo. Assim, ele já nem fala nada no dia em que não estiver se sentindo bem, para não ter que enfrentar outro risco, que é a ridicularização por parte do grupo.

No desenvolvimento de prevenção à segurança do trabalho, quanto à implicação de diferentes profissionais numa mesma ação, o advento das especializações não é diferente. $\mathrm{O}$ cuidado com a segurança nas empresas pressupõe uma intervenção multidisciplinar que vai muito além do conhecimento técnico. Há uma série de aspectos que devem ser atentados para garantir o cuidado com o trabalhador.

Uma das questões, por exemplo, diz respeito ao investimento financeiro realizado pelo trabalhador com seu salário. Dada a presente oferta facilitada de crédito, não raro, alguma pessoa do grupo se vê absolutamente endividada. Isso cria problemas graves ao sujeito, que se vê do dia para a noite "desonrado" pela perda do nome limpo na praça e lhe proporciona sofrimentos específicos. Os salários, geralmente baixos apesar dos riscos e especificidades do setor elétrico, não são suficientes para a manutenção das famílias, $o$ que resulta em muitas horas extras e um trabalhador potencialmente exausto.

Nestas circunstâncias, é até comum, pelas observações que fizemos da rotina da empresa, que a própria disponibilize um consultor para auxiliar o trabalhador, ou até mesmo lhe ofereça alguma quantia em dinheiro para tentar reverter a situação. Obviamente a empresa não age sem interesses, posto que compreende, através da sua gestão, a especificidade do risco que se submete o eletricitário. Por essa lógica, evitar tais aborrecimentos aos funcionários é entendido como uma medida de minimização dos riscos. Contudo, também é uma maneira de "fidelizar" o trabalhador e garantir que ele vá trabalhar com maior dedicação na empresa, instituição que lhe garantiu a "salvação" dos seus problemas (afinal, não é uma mão-de-obra fácil de conseguir).
Por tudo isso, enfatizamos dois pontos: a larga aplicação que o trabalho de minimização dos riscos pode ganhar e as estratégias escondidas que podem transformar um risco em outro. Até porque, tendo um funcionário que seja efetivamente "fiel" à empresa, é mais fácil de garantir que este venha a aceitar certos padrões que the coloquem em desvantagem, como o não pagamento de todos os direitos sociais ou a carga excessiva de trabalho. As relações de trabalho capitalistas historicamente também produzem as históricas desigualdades entre as classes sociais, e o imperativo da acumulação capitalista é um fator, muitas vezes, impeditivo para que se tomem medidas realmente prevencionistas do risco no trabalho.

Chamamos a atenção para este fator, uma vez que "ambientes institucionalizados de risco geram algumas situações dentro das quais os indivíduos podem escolher recursos escassos, inclusive suas vidas" (Giddens, 2002, p. 118).

Fato é que o auxílio concedido pela empresa, seja de suporte financeiro ou de qualquer outra ordem, é pouco significativo, em termos de investimento, para a organização, mas faz uma diferença realmente grande para o sujeito que individualmente o recebe. Eventualmente, essa relação pode tornar-se perversa no sentido da geração de dependência e aceitação de condições piores de trabalho, aceleração do ritmo e equipes diminutas, por uma suposta "gratidão".

Assim, é preciso estar atento quanto aos eventuais benefícios oferecidos pelas empresas e fazer uma análise profunda e séria dos antagonismos presentes em cada ação. Isso não nos leva a crer que as instituições devam deixar de auxiliar os seus funcionários, ao contrário, mas nos sugere, como profissionais das ciências humanas, certa cautela quanto à implementação de determinados programas aparentemente favoráveis ao trabalhador, mas que podem se transformar facilmente em poderosos mecanismos de coerção.

\section{Sobre isso,}

a aceitação passiva dos perigos de certas práticas como dirigir ou fumar por amplos setores da população deve ser interpretada, em parte considerável, de maneira diferente. Dois tipos de interpretação têm sido oferecidos. Uma é das grandes corporações e outras agências poderosas que conspiram para enganar $o$ público sobre o verdadeiro nível de risco, ou usam a propaganda e outros métodos para assegurar que uma proporção substancial da população se envolva nesses hábitos de risco. A outra sugere que a maioria dos leigos não é sensível ao risco individualmente distribuído ou adiado - ainda que reajam fortemente 
a desastres coletivos ou a riscos mais "visíveis". (Giddens, 2002, p. 118)

Ao falar acerca do risco, ele vai se tornando cada vez mais presente para o trabalhador (por isso a evitação já mencionada, parte das defesas coletivas grupais): "Mas o nosso trabalho não dá pra dizer que em algum momento não é arriscado. Ele é arriscado de todas as maneiras" (Jaime).

$\mathrm{Na}$ rotina das empresas, existem muitos procedimentos que, embora envolvam risco, não são considerados enquanto tal. Da parte dos trabalhadores, minimizar os riscos serve também como um mecanismo de defesa para conseguir suportar a convivência com tantos eventos perigosos. No setor elétrico, muitas das práticas, mesmo as que envolvem riscos, são muitas vezes desconsideradas justamente por implicar num risco maior: a perda do emprego.

E tem sempre aquele que, quando tu desiste de um serviço, olha por trás e diz: mas aquilo lá eu sei que dá pra fazer. Tu subiu e sabe que não dá pra fazer. E ai? Tu tem uma família pra sustentar, tem aluguel... Aquele que subiu lá e viu o problema sabe que é arriscado. Que vai mexer lá e sei lá, né... Subiu e viu que não dava, que não tava firme e tudo. Desce e tem o outro que fala 'mas eu fazia aquilo lá'. (Rocha)

O medo de ver-se fora do mercado de trabalho, sendo por vezes o único responsável pelo sustento da família, faz com que os riscos, ainda que conhecidos, se tornem aceitáveis. Existe todo um discurso, não só informal como também midiático, de que o ser humano deve dar o melhor de si para garantir um bom futuro para a sua família.

\section{Dai é porque é quatro horas, ou três e meia a hora que nós chegamos ou não chegamos. Põe uma pressão, né. E aquele que subiu tem o aluguel pra pagar, tem filho pra sustentar, tem colégio e tudo. É uma coisa bem... é complicado. Porque hoje em dia tu te obriga a fazer coisas que tu não deveria fazer. Tem que dar uma olhadinha em volta pra ver como tá o ambiente e... abafar, né. (Jaime)}

Nessas narrativas, fica implícito que o sujeito é o único responsável pelo seu mérito ou demérito, como se não houvesse todo um sistema de divisão social do trabalho altamente articulado que impõe empecilhos e dificuldades reais. Nossa pesquisa mostrou que o medo de deixar a família em más condições e, com isso, ser visto como alguém incapaz supera o medo de sofrer algum acidente de trabalho. Outro aspecto que depreendemos da fala do trabalhador é o tempo, a temporalidade. Notamos a visível exigência de se fazer o trabalho no tempo determinado, mesmo que o discurso manifesto da empresa seja outro, que não haverá pressão etc. A pressa existe e vira fator de coerção e fonte de riscos específicos ao psiquismo. Além disso, a atividade laboral acaba tomando grande parte da vida dos sujeitos em termos de tempo, pois, conforme relatam, as horas-extras fazem-se necessárias para complementar o ganho financeiro. Para Dejours (1988, p. 45), "se levarmos em conta o custo financeiro das atividades do trabalho e do tempo absorvido pelas atividades inelásticas (tarefas domésticas, deslocamentos), poucos são os trabalhadores que conseguem organizar o lazer de acordo com seus desejos e necessidades fisiológicas".

Ao ser questionado sobre quais seriam seus planos para o futuro, um dos trabalhadores responde: "Trabalhar para pagar as contas. Salvem-se quem puder das dívidas!" (Rocha).

Por esta razão, entendemos que "o planejamento da vida" considera um 'pacote' de riscos. Em outras palavras, assumir certos riscos na busca de certo estilo de vida é aceito como dentro dos 'limites toleráveis' do pacote como um todo" (Giddens, 2002, p. 118). Esses limites por vezes podem se tornar algo muito arriscado. Segundo o diálogo de dois dos funcionários do grupo focal, as instaladoras elétricas não deixam claro que a recusa ao contato com o risco pode causar demissão. Porém, na prática, as coisas não funcionam bem assim.

Mas, por exemplo, se eu aqui de repente, tem lá na NR10, acho que é, que tem o item de recusa. Eu posso me recusar a fazer uma tarefa desde que eu possa provar que aquilo lá tá me colocando em risco. Eu posso me recusar. Mas tem umas empresas ai que tu tem esse direito, mas que, se tu recusar, ele... (Rocha)

Tu tá "fudido". (Mirto)

Tá demitido. Isso é uma realidade. (Rocha)

Real ou imaginário, o medo de ser demitido existe e atormenta o trabalhador. Os funcionários não chegam a relatar um caso específico no qual um colega perdeu o emprego em função disso, procurando salientar que esta empresa é, de fato, uma boa empresa para se trabalhar, inclusive no que diz respeito à segurança. Todavia, ao discutirem o tema nos grupos focais, aparece claramente o receio da possibilidade de demissão.

Boa parte da estimativa de risco se dá ao nível da segurança prática e ... o casulo protetor da confiança básica bloqueia a maioria dos eventos potencialmente perturbadores que interferem nas circunstâncias de vida do indivíduo. Estar "à vontade" no mundo é certamente problemático na era da alta modernidade, em que o referencial de "atenção" e o desenvolvimento de "histórias compartilhadas" com 
os outros são realizações basicamente reflexivas. (Giddens, 2002, p. 119)

De todo modo, o conflito entre os trabalhadores, sendo desta ou de qualquer outra empresa, é uma das consequências de um mercado de trabalho que põe os sujeitos a competir diretamente por uma questão de sobrevivência. Essa característica, quando presente numa realidade em que o trabalho deve acontecer de maneira cooperada, só faz aumentar o risco presente na situação de trabalho. Da mesma forma, aumenta a preocupação por medidas que promovam maior grau de cooperação no trabalho de grupo.

\section{Considerações finais}

A noção de trabalho, no âmbito do capitalismo, é central ao entendimento do risco, na medida em que impõe padrões de produção e consumo que afetam sociopsicologicamente os sujeitos, inclusive ao normatizar os rumos e desejos de suas próprias vidas - que acabam, via de regra, sendo guiadas pelo trabalho. $\mathrm{O}$ setor de segurança nas empresas, embora venha mudando positivamente ao longo dos anos, ainda demanda muito desenvolvimento teórico e prático acerca do cuidado com o trabalhador. Em especial, e provavelmente por se tratar de um campo de conhecimento técnico, há uma falta expressiva do entendimento do risco na dimensão psicossociológica, subjetiva, ainda que produzida socialmente, o que prejudica a qualidade das intervenções de segurança do trabalho.

Muitas destas instâncias as quais nos referimos estão enraizadas no que ainda se admite enquanto subsequente ao modelo capitalístico - de produção, de compra, de venda - ou seja, de sobrevivência. Esta esfera, por estar atrelada aos modos de vida da sociedade contemporânea num sentido irrestrito, nos deixa pouco espaço para pensar em grandes mudanças no cenário do trabalho que não sejam levadas a cabo pelo caminho da política.

Corroborando com a dimensão política, podemos pensar intervenções no âmbito da dimensão sociopsicológica do risco. Os empresários ou demais responsáveis pela gestão da segurança nas empresas podem ser convocados ao debate, o que inclui a participação de uma equipe multidisciplinar minimamente capaz de abarcar as dimensões do risco e intervir ativamente na perspectiva prevencionista, o que inclui problematizar a lógica produtivista, as relações de poder e hierarquia nas empresas. Aos funcionários, por sua vez, se torna importante um espaço de escuta e acolhida, garantido pela imparcialidade de quem o conduza, onde os medos possam encontrar um ambiente de produção livre de sentidos, sendo ressignificados. A criação desse espaço permanente poderá ser um instrumento importante na diminuição das incidências de utilização dos mecanismos de defesa e eufemização do risco por parte dos trabalhadores.

Quanto aos que cuidam da segurança do trabalho, é notável um distanciamento entre as ciências humanas e as engenharias, o que dificulta o trabalho multidisciplinar. As questões a respeito do risco ainda são pouco discutidas - inclusive academicamente - e se tem dificuldades de criar um diálogo comum entre o que se produz numa esfera sociopsicológica e na ergonômica (aqui entendida como uma das áreas da engenharia de segurança).

O trabalhador pode ser punido quando dispensa os procedimentos de segurança para tornar mais rápido o processo de trabalho. Contraditoriamente, é cobrado por produção e rapidez de execução. O que coloca, geralmente, no plano do invisível o lugar ou os agentes de onde vem a cobrança pelo trabalho mais ágil. Aqui há um ponto nevrálgico da questão da segurança que, por ser de difícil equação, geralmente é ignorado por direção, gestão e trabalhadores.

O trabalho do profissional atento ao cuidado psicossocial dos trabalhadores em empresas - assim abrangemos a participação de todo e qualquer cuidador, indiferente da sua formação (enfermagem, medicina, psicologia, engenharia, técnico) - é um grande desafio. Contar com uma equipe interdisciplinar de cuidado e prevenção ao risco, bem preparada para tal, é a prerrogativa primeira. Esta equipe precisa manter um diálogo próximo, atento às demandas dos trabalhadores e disposta a entrar em certo atrito com segmentos das empresas, como o de produção, financeiro, vendas, diretoria etc.

A rotina de muitas empresas ainda põe a segurança, de modo geral, num plano secundário. Assim, as pessoas que cuidam da segurança fazem parte de um setor específico, subordinado, que criam algumas normas para a empresa, mas nem sempre opinam quando regras são criadas para acelerar a produção, por exemplo, não sendo incluídas nas discussões que geram decisões estratégicas na empresa. "Tu precisa ter líderes e administradores que tenham o pulso firme, que falem com a mesma língua, que deem exemplos de segurança", afirma o trabalhador Teodoro.

Quem administra, como vimos, não é a mesma pessoa que se preocupa formalmente com a segurança; isso faz com que essa 'mesma língua' seja algo absolutamente utópico em se tratando do 
dia a dia da organização, por mais que os gestores estejam preocupados com a segurança e os técnicos de segurança com a produção.

Do ponto de vista político, há a urgência de se levar adiante a realidade da segurança do trabalho aos ambientes de troca politicamente reconhecidos - sejam estes sindicatos, conselhos, associações de bairro ou demais organizações sociais - mantendo o diálogo permanente com os próprios trabalhadores que são expostos aos riscos de qualquer ordem. Notase um enfraquecimento dos referidos movimentos em prol do trabalhador, pois mesmo quando efetivam tal diálogo, tendem a centralizar a discussão num aspecto específico, como a redução da jornada de trabalho, por exemplo. Assim, os múltiplos riscos, alguns invisíveis, acabam esquecidos e continuam ameaçando a saúde do trabalhador e a sociedade como um todo.

Para tanto, diferentes formas de saber devem ser respeitadas para que o diálogo possa vir a acontecer. Isso inclui tanto a possibilidade de interlocução das áreas da engenharia com as ciências sociais, quanto do técnico de segurança com o operário, ambas envoltas na complexidade da estrutura do trabalho capitalista já mencionado.

Esses desafios e possibilidades se colocam ao profissional de psicologia ou sociologia dentro das empresas. Intervir nos conflitos produzidos pela relação capital-trabalho é tarefa difícil, mas extremamente necessária e relevante.

É por este outro desenho de relações de trabalho que começamos a pensar na criação de condições de modos de vida mais seguros e dignos aos sujeitos que vivem do trabalho ${ }^{4}$. Cabe a todos que atuam na área construí-los, almejando assim a emancipação das condições de opressão que envolvem o risco.

\section{Notas}

1 A coleta dos dados deu-se em uma empresa de montagem de redes elétricas, situada na cidade de Garibaldi-RS, entre os anos de 2009 e 2010.

2 O nome dos participantes foi alterado para garantir o sigilo da pesquisa.

3 Normas Regulamentadoras de Segurança em Instalações Elétricas.

4 Termo utilizado por Ricardo Antunes.

\section{Referências}

Bardin, L. (1995). Análise de conteúdo. Porto: Edições 70.

Beck, U. (2002). La sociedad del riesgo global. Madri: Siglo Ventiuno.

Dejours. C. (1988). A loucura do trabalho: estudo de psicopatologia do trabalho. São Paulo: Cortez.

Dejours. C. (1994). Psicodinâmica do trabalho. São Paulo: Atlas.

Dejours. C. (1999). A banalização da injustiça social. Rio de Janeiro: FGV.

Dejours. C. (2003). Fator humano ( $4^{\mathrm{a}}$ ed.). Rio de Janeiro: FGV. Giddens, A. (1989). A constituição da sociedade. São Paulo: Martins Fontes.

Giddens, A. (2002). Modernidade e identidade. Rio de Janeiro: Jorge Zahar.

Nogueira, V. A. (1999). Reestruturação do setor elétrico: um estudo qualitativo das condições de trabalho e saúde dos eletricitários frente à privatização da CERJ. Dissertação de Mestrado, Programa de Pós-graduação em Saúde Pública, Fundação Oswaldo Cruz, Escola Nacional de Saúde Pública, Rio de Janeiro.

Possamai, H. \& Guareschi, P. (2007). Minha culpa, meu destino: representações sociais dos acidentes de trabalho. In P. A Guareschi \& M. V. Veronese (Orgs.), Psicologia Social e cotidiano: representações sociais em ação (pp. 225-246). Petrópolis, RJ: Vozes.

Serrano, J. L. (2009). Diferença Risco/Perigo. Novos Estudos Jurídicos, 14(2), 233-250.

Submissão em: 24/02/2014

Revisão em: 26/05/2015

Aceite em: 03/07/2015

Julice Salvagni é doutora em Sociologia pela UFRGS e bolsista do Programa Nacional de Pós Doutorado da CAPES pelo PPG em Ciências Sociais da Unisinos. E-mail: julicesalvagni@gmail.com

Marília Veríssimo Veronese é doutora em Psicologia Social pela Pontifícia Universidade Católica do Rio Grande do Sul (2004). Atualmente é professora Titular I da Universidade do Vale do Rio dos Sinos (UNISINOS). Endereço para correspondência: Universidade do Vale do Rio dos Sinos. Av. Unisinos, 950 - Cristo Rei, São Leopoldo/RS, CEP 93022-000. Programa de Pós-Graduação em Ciências Sociais, Prédio: B09, sala B 09440. E-mail: mariliav@unisinos.br 